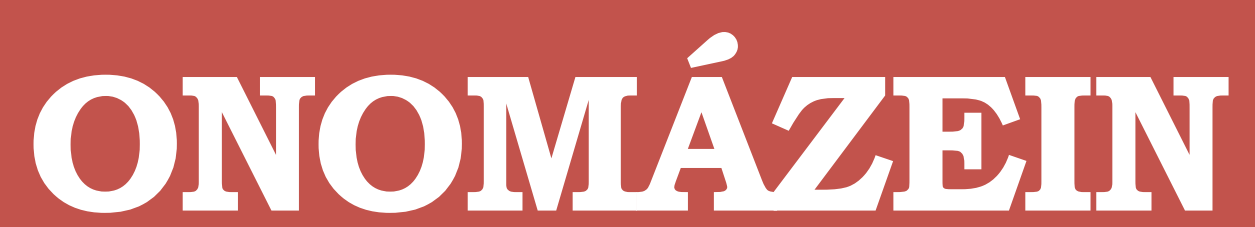

Revista de lingüística, filología y traducción
PONTIFICIA UNIVERSIDAD CATÓLICA DE CHILE FACULTAD DE LETRAS

\title{
El graffiti como motor del pensamiento crítico en lengua extranjera
}

Graffiti as the driving-force of critical

thinking in teaching a foreign language

\section{Carmen Aguilera Carnerero}

Universidad de Granada

Número especial $-\mathbf{V I}-$

Investigación en enseñanza

de lenguas desde una perspectiva global

2020
ONOMÁZEIN | Número especial VI - Investigación en enseñanza de lenguas desde una perspectiva global: 189 -208 DOI: 10.7764/onomazein.ne6.10

ISSN: 0718-5758

\section{(c) $($ i $)$}

Carmen Aguilera Carnerero: Departamento de Filologías Inglesa y Alemana, Universidad de Granada. | E-mail:carmacar@ugr.es

Fecha de recepción: 24 de julio de 2018

Fecha de aceptación: 22 de diciembre de 2019 


\section{Resumen}

Este artículo plantea una propuesta educativa que reivindica la inclusión del graffiti como objeto de estudio de una asignatura de español para extranjeros. Además de su infravalorado potencial desde una perspectiva meramente lingüística (como texto escrito), el graffiti puede resultar, sobre todo, una magnífica herramienta pedagógica que promueva el pensamiento crítico y la formación de ciudadanos intelectualmente activos. La incorporación del graffiti al currículo académico se justifica por la existencia de un marco educativo que prima la transversalidad como eje central para superar la mera concepción de la enseñanza como transmisión de conocimientos, así como alienta el desarrollo de alumnos capaces de aplicar los mismos para adquirir un compromiso social.

Palabras clave: graffiti; pensamiento crítico; español como lengua extranjera; transversalidad.

\section{Abstract}

This paper puts forward an educational proposal that reclaims the role of graffiti as the object of study of the subject of Spanish for foreign students. Letting aside its underused didactic potential from a linguistic perspective (as a written text), the graffiti can also be considered as a wonderful pedagogical tool that promotes critical thinking and the training of intellectually active citizens. The inclusion of graffiti in the curriculum is backed up by an educational framework that gives priority to transversality as the backbone that allows the improvement of pedagogy as just the transmission of knowledge and fosters the development of students capable to apply them to become socially engaged.

Keywords: graffiti; critical thinking; Spanish for foreign students; cross-curricular issues.

1 Aunque la Real Academia de la Lengua Española (RAE) solo reconoce como término aceptado la grafía "grafiti" (https://dle.rae.es/?w=grafiti), en este capítulo hemos decidido adoptar la variante "graffiti", más cercana a la original, por ser la que aparece en toda la bibliografía en español consultada tanto de español peninsular como latinoamericano. 


\section{Introducción: ¿Qué es el graffiti?}

Cualquier habitante de un entorno urbano está acostumbrado a convivir con paredes y muros decorados con mensajes de distinto tipo que, en la gran mayoría de ocasiones, se han llevado a cabo en contra de la voluntad del propietario del edificio en el que están localizados, bien sea este un ciudadano individual o una institución pública. Al contemplar un graffiti, las reacciones del viandante son múltiples: lo ignora, lo observa, sonríe, se siente incómodo o muestra su desacuerdo con lo que lee.

El graffiti suele tener connotaciones negativas y su práctica suele estar asociada a los delitos urbanos, tal y como lo explica la "teoría de las ventanas rotas". La imagen de ventanas rotas en un vecindario está íntimamente unida al vandalismo y, en consecuencia, a la actividad criminal.

Los historiadores suelen retrotraer el origen del graffiti a las pirámides de Egipto, los restos que permanecen tras la erupción del Vesubio en Pompeya o los edificios medievales (Garí, 1995). Arañar, escarbar y pintar mensajes en las paredes (bien sean símbolos o letras) no es un fenómeno reciente.

Grosso modo, las dos grandes tradiciones que han imperado en el desarrollo del graffiti en el siglo XX (Silva, 1988) son a) la de Mayo del 68, con un marcado cariz político y que básicamente consistía en eslóganes contra la autoridad escritos en la pared con propósitos macropolíticos, y b) el graffiti de Nueva York, que suele ser clandestino, figurativo, contener autorreferencias al ghetto y tiene objetivos micropolíticos 3 .

El graffiti se revela como una práctica íntimamente asociada a la historia de la humanidad; sin embargo, la primera y primordial pregunta que surge es: ¿qué es un graffiti? Dar respuesta a esta cuestión se convierte en algo más difícil de lo que pudiera parecer a simple vista; en este trabajo partiremos de la definición proporcionada por Silva (1988: 28):

La inscripción urbana que llamamos graffiti corresponde a un mensaje o conjunto de mensajes, filtrados por la marginalidad, el anonimato y la espontaneidad y que en el expresar aquello que comunican violan una prohibición para el respectivo territorio social dentro del cual se manifiesta.

Es pertinente aclarar que, en este artículo, solo nos centraremos en el graffiti, entendiendo como tal los mensajes escritos (acompañados o no por imágenes) realizados en espacios

2 Esta teoría fue formulada por los criminólogos Kelling y Wilson en 1982 en la revista de información general The Atlantic (https://www.theatlantic.com/magazine/archive/1982/03/broken-windows/304465/).

3 Esta clasificación es coincidente con la de Baudrillard (1974). 
públicos de manera clandestina, excluyendo de nuestro estudio el llamado "arte urbano" o aquellas creaciones más artísticas en las que la forma prevalece sobre el contenido del mensaje escrito, si estuviera presente.

El objetivo fundamental de este trabajo es justificar las ventajas didácticas que puede tener la incorporación del graffiti a una asignatura de enseñanza de español como lengua extranjera. Para ello, nos basaremos en un estudio previo en el que analizamos un corpus de graffiti recogido en Granada (España) y observamos la gran variedad de grupos marginalizados socialmente que se expresan a través de este género. Es este componente social del graffiti el que lo convierte en un elemento idóneo para enseñar las competencias sociopragmáticas y los aspectos culturales del español.

\section{Marco teórico}

\subsection{El graffiti en los estudios académicos}

El graffiti ha captado la atención y el interés de académicos que lo han estudiado desde diferentes perspectivas durante décadas. En su revisión exhaustiva de la literatura sobre el tema, Gadsby (1995) identifica nueve grandes enfoques que incluirían categorías como la cultural, la de género, la folclórica, la cuantitativa, la estética, la motivacional, la preventiva, la popular y la lingüística.

Distintos trabajos se aproximan al tema desde una perspectiva lingüística, si bien desde muy diversos ángulos. Blume (1985), al igual que Gándara (2002), adopta un enfoque discursivo, mientras que Breva Claramonte y García Alonso (1993) estudian la morfología, la ortografía y el uso de jerga en el texto. Garí (1995) analiza de manera exhaustiva el fenómeno del graffiti desde una perspectiva semiótica y pragmática, y Ugarte García (2012) presta especial atención a la fraseología.

Pérez Sendra (2017) menciona la proliferación de los talleres y cursos de graffiti en España los últimos años además de, aunque de forma más tímida, su introducción en asignaturas en los grados universitarios de Bellas Artes y en las clases extraescolares en centros de primaria y secundaria. Sin embargo, todos los estudios a los que alude incluyen al graffiti como objeto de estudio artístico o giran en torno a los aspectos presentes en su producción. La explotación didáctica del graffiti como recurso lingüístico y como catalizador del pensamiento crítico ha sido infravalorada en los estudios de educación secundaria y superior. Nuestro planteamiento pretende paliar parcialmente este vacío con su incorporación al currículo como objeto de estudio fundamentalmente lingüístico, pero además como herramienta que ayude a los alumnos a comprender el contexto social en el que se produce la lengua que estudian. 


\subsection{Pensamiento crítico, educación social y transversalidad}

Además de los múltiples aspectos lingüísticos que puedan resultar atractivos en el análisis del graffiti, nuestra propuesta para su inclusión como objeto de estudio se apoya en tres pilares fundamentales: la noción de pensamiento crítico, el concepto de pedagogía de Paulo Freire y la idea de transversalidad.

Ya hace dos décadas que Travé González y Pozuelos Estrada (1999), al analizar el tratamiento tradicionalmente otorgado al enfoque de estudio de las demandas sociales, hablaban de un entorno sociológico desintegrado y antihumanista que había sumido a la escuela en una profundísima crisis de valores, pensamiento compartido por otros autores como Díaz Barriga (2006). “La finalidad de la educación [...] debe superar su consideración de acto reproductor de la cultura dominante para pasar a ser un proceso transformador de la propia realidad social" (Travé González y Pozuelos Estrada, 1999: 9).

La transformación a la que se refiere la cita anterior está íntimamente ligada a la formación de ciudadanos libres y comprometidos socialmente y en la que ocupa un lugar primordial la noción de pensamiento crítico. En este artículo adaptaremos la definición del concepto proporcionada por Halpern (2003: 6-7), que enfatiza su aplicación práctica con resultado positivo:

El pensamiento crítico es el uso de las destrezas cognitivas o estrategias que incrementan la probabilidad de un resultado deseable. El término se utiliza para describir el pensamiento que tiene un propósito, que es razonado y está orientado hacia un fin [...]; no es solo pensar sobre tus propias ideas [...], es utilizar las destrezas que tendrán con más probabilidad "resultados deseables". Decisiones como qué resultados son los deseables están insertadas en un sistema de valores.

La importancia del pensamiento crítico en el contexto educativo fue por primera vez subrayada a partir de la taxonomía propuesta por Benjamín Bloom (1956) hace varias décadas (Lauer, 2005; Duron y otros, 2006). Se equiparaba un más alto nivel de habilidad cognitiva con actividades como el análisis, la síntesis y la evaluación, en las que el pensamiento crítico era un rasgo presente, mientras que los niveles más bajos de habilidad cognitiva solo implicaban recordar, relacionar y aplicar la información necesaria (Duron y otros, 2006). El pensamiento crítico no debe de ningún modo concebirse como una amenaza al conocimiento disciplinar, sino que, como Zabala (1995) explica, se trata de reconsiderar la posición hegemónica y exclusiva que se le ha dado a este en el currículo educativo.

Un aspecto vital en la incorporación del pensamiento crítico en educación es el papel del docente dentro de todo el proceso. El docente deber ser flexible (Black, 2005) y mostrar una multiplicidad de soluciones posibles frente a cualquier problema planteado, así como recon-

4 La traducción es nuestra. 
siderar la manera en la que la información se dirige y transmite a los estudiantes. En este sentido, Duron y otros (2006) apuntan que el formato de clase magistral, que continúa siendo un enfoque popular en la educación superior en muchas partes del mundo, podría no ser el marco más idóneo. Los profesores además tienen que aceptar que los estudiantes pueden instruirse sin necesidad de ser "enseñados"5 (Choy, 2003).

Inevitablemente ligada al concepto de pensamiento crítico está la revolucionaria noción de educación social formulada por Paulo Freire (1971, 1994), que supuso un punto de inflexión en la pedagogía del siglo XX.

Afirma Giroux (2010) que la pedagogía ha estado subordinada a un régimen estrecho de enseñanza enfocada al éxito en el examen y que además, con frecuencia, va emparejada con un sistema severo de control disciplinario. Ambos aspectos, la enseñanza orientada a aprobar el examen y el tinte empresarial que ha adquirido la educación, además de reforzarse mutuamente han llegado a ser una forma de "amansar" a los estudiantes a la par que un número creciente de profesores de la escuela pública se han convertido en la nueva clase de subalternos académicos. Freire (1994), en dirección diametralmente opuesta, concibió la pedagogía como parte de una práctica democrática más amplia destinada al cambio, razón por la que la pedagogía crítica nunca fue considerada ni como un discurso ni como una metodología que debiera implementarse.

Como Giroux (op. cit.) explica, para Freire (1994) toda educación en el sentido más amplio es parte de un proyecto de libertad eminentemente político porque solo ofrece a los estudiantes las condiciones para la propia reflexión, una vida autogestionada y las particulares nociones de agentividad crítica.

Este planteamiento, por definición, cuanto menos crea inquietud en las autoridades educativas, ya que la pedagogía crítica abre un espacio para que los estudiantes se reconcilien con su propio poder como ciudadanos involucrados, proporciona un espacio público donde la libertad ilimitada para cuestionarles y afirmarse es central al propósito de la educación pública y la educación superior.

Una idea aparejada al estudio del graffiti dentro de una asignatura de enseñanza de lenguas es el concepto de transversalidad, que Tobón (2013: 21) define de manera pormenorizada:

La transversalidad consiste en abordar un problema con los saberes de varias disciplinas, áreas o campos con el fin de lograr una comprensión y resolución más integral y sistémica, así como tener mayor impacto y trascendencia en los productos que se buscan. En el campo formativo, la transversalidad permite que los estudiantes aprendan a articular los saberes de varias disciplinas en

5 Las comillas son nuestras. 
un problema del contexto y esto les ayuda a tener mejor comprensión de los contenidos. Además, acerca el mundo educativo con el mundo social, dado que en la vida cotidiana los problemas son transversales y requieren de varias disciplinas para poderse resolver.

Munévar y Villaseñor explican el origen del concepto como la consecuencia inevitable de la relación entre problemas sociales y educación (2005: 46):

Los ejes transversales surgen de necesidades y demandas que la sociedad plantea a la educación. Por ello, más que atender a los contenidos cognitivos, los ejes nos plantean retos referidos a la formación integral de los individuos en dirección a lograr una ciudadanía plena y, como una característica común a todos ellos, en última instancia se relacionan también con valores.

La transversalidad no es una noción ajena a la crítica, lógicamente. Travé González y Pozuelos Estrada (1999) a finales del s. XX se quejaban de que, aunque la vocación del concepto fue la de integrar los problemas y las demandas sociales en el currículo obligatorio, en la práctica estaba sirviendo de escaparate a modas escolares.

En el ámbito español, la inclusión de temas transversales en el currículo fue realizada por Coll en 1991. Los temas transversales, aquellos que "atraviesan" el currículo tanto vertical como horizontalmente (Martínez, 1995), son la educación moral y cívica, la educación ambiental, la educación para la salud y sexual, la educación en igualdad de oportunidades para ambos sexos, la educación para la paz, la educación del consumidor y la educación vial. Como bien describen Travé González y Pozuelos Estrada (1999: 7), "al transgredir los estrechos márgenes de las disciplinas científicas para dar solución a los problemas sociales se permite el desarrollo de los alumnos de pensamiento crítico y su consecuente intervención en la realidad social”.

\subsection{Marco común europeo de referencia para las lenguas y plan curricular del Instituto Cervantes}

La inclusión del graffiti como parte del currículo académico de la asignatura de español como lengua extranjera se justifica ampliamente en las directrices establecidas por el Marco común europeo de referencia para las lenguas (Instituto Cervantes, 2002) (en adelante MCER). EL MCER es un documento elaborado por el Consejo de Europa resultado de un proyecto iniciado en 1991 y actualmente traducido a más de 20 lenguas (la traducción al castellano data de 2002). La idea central del proyecto es que un mayor conocimiento de las lenguas modernas de Europa es esencial para facilitar la comunicación, la interacción y el intercambio de los ciudadanos.

EI MCER hace hincapié en la competencia comunicativa junto con las subcompetencias que la integran: Ia competencia lingüística, la sociolingüística y la pragmática. El documento subraya además la dimensión del uso social de la lengua que queda englobada dentro de la competencia sociolingüística, al ser la lengua un fenómeno eminentemente sociocultural. 
Según el MCER, el desarrollo de las competencias comunicativas de la lengua no va necesariamente aparejado al conocimiento del mundo y a prácticas sociales e interculturales, un aspecto que la enseñanza del graffiti puede paliar de manera eficiente.

El plan curricular del Instituto Cervantes ${ }^{6}$ asimismo recoge las líneas establecidas por el MCER, y en la introducción de habilidades y actitudes interculturales del documento se afirma que

[...] la comunicación trasciende el mero intercambio de información para abarcar la comprensión, la aceptación, la integración, etc., de las bases culturales y socioculturales comunes que comparten los miembros de las comunidades a las que accede el alumno: la memoria histórica, las formas de vida, los valores, las creencias, etc., que a menudo impregnan la literatura, el cine, las artes plásticas, etc.

De hecho, se menciona específicamente7 que el desarrollo de la competencia sociolingüística del alumno (véase la sección 5.2.2) se puede transferir desde su propia experiencia de la vida social o, en caso de carecer de ella, se le puede facilitar o bien mediante la exposición a la lengua auténtica que se utiliza de manera adecuada en su entorno social o bien mediante la selección y construcción de textos que ejemplifiquen los contrastes sociolingüísticos existentes entre la sociedad de origen y la sociedad meta.

El segundo apartado, procesamiento y asimilación de saberes culturales y comportamientos socioculturales; el tercero, sobre interacción cultural, y el cuarto, que se centra en la mediación intercultural, convierten al graffiti en un producto ideal de aprendizaje del español en el que la estructura lingüística va inevitablemente aparejada al contexto sociocultural, es más, es producto de este.

\section{Metodología y corpus de estudio}

\subsection{Enfoque metodológico: análisis crítico del discurso (ACD)}

El enfoque teórico escogido para realizar una taxonomía del material compilado fue el análisis crítico del discurso (ACD). Aunque la heterogeneidad es uno de los rasgos definitorios del ACD (Hidalgo Tenorio, 2011), Van Leeuwen (2009) afirma con certeza que todos los enfoques tienen como objetivo común la crítica de los discursos dominantes que provocan desigualdades, injusticias y opresión en la sociedad contemporánea. En particular, nuestro estudio estuvo influido por Fairclough (1995) y sus principios de la descripción del lenguaje, la interpretación de los procesos discursivos presentes en el texto y la explicación de la relación entre los procesos discursivos y sociales.

6 Al plan curricular del instituto Cervantes se puede acceder aquí: https://cvc.cervantes.es/ensenanza/biblioteca_ele/plan_curricular/default.htm.

7 El marco común europeo de referencia para la enseñanza de lenguas puede consultarse en https:// cvc.cervantes.es/ensenanza/biblioteca_ele/marco/cap_06.htm\#p648. 


\subsection{Corpus de estudio}

Nuestro corpus de estudio previo consta de 187 graffitis fotografiados en distintas partes de Granada (España) que comparten un par de características formales:

a) Se encontraban en el exterior. Se descartaron los graffitis escritos en los pupitres de la universidad o en los aseos públicos, por ejemplo. Todos los textos del corpus se encontraron en la calle.

b) Tenían que contener un texto escrito (desde palabras aisladas hasta oraciones completas), que podía estar o no acompañado por imágenes.

Todos los graffitis incluidos en el corpus fueron creados de manera clandestina debido a su localización en lugares públicos en el exterior. Una vez compilados, procedimos a realizar una clasificación basada en el contenido temático a partir de la cual poder analizar los rasgos lingüísticos de cada grupo.

Los objetivos fundamentales en el análisis del corpus fueron tres:

a. Elucidar los diferentes tipos de discursos marginales presentes en el graffiti.

b. Describir su fuerza comunicativa a través del análisis de las estructuras lingüísticas.

c. Identificar los actores sociales que se visibilizan y logran empoderarse a través de su representación en el discurso público del graffiti.

\section{Resultados y análisis}

El corpus se clasificó en distintas categorías de acuerdo con el tipo de comentario social que contenía y los actores participantes en la creación del discurso tal y como puede verse abajo en la tabla I:

\section{TABLA 1}

Distribución de los diferentes tipos de graffitis en el corpus. Fuente: elaboración propia

\begin{tabular}{|c|c|}
\hline TIPO DE GRAFFITI & NÚMERO DE EJEMPLOS EN EL CORPUS \\
\hline Feminista & 47 \\
\hline Anticapitalista & 18 \\
\hline Antisistema & 30 \\
\hline Anticlerical & 4 \\
\hline Pro derechos de los animales & 10 \\
\hline Poético/Filosófico & 78 \\
\hline Total & 187 \\
\hline
\end{tabular}


A continuación, pasamos a describir brevemente las características lingüísticas fundamentales de los distintos tipos de graffiti en el corpus.

\section{a) Graffiti feminista}

Dentro de la categoría genérica de graffitis que tienen como objetivo la reivindicación de los derechos de la mujer, se distinguen dos tipos diferenciados de estructuras lingüísticas: una está constituida por los textos en los que el mensaje selecciona un particular grupo de receptores, bien sea el colectivo de mujeres, "ante la duda, tú la viuda” (figura 1), "ni te cases ni te sometas", o se dirigen directamente a los hombres machistas y la sociedad patriarcal en general, como "ni la tierra ni las mujeres somos territorios de conquista".

Este tipo de graffitis contiene mensajes muy elaborados sintácticamente, sobre todo realizados por proposiciones en las que las mujeres están siempre representadas, bien a través de un vocativo ("mujer") con el que son exhortadas para tomar acción, bien por la utilización de verbos en primera persona ("somos", "estamos", "matamos") o pronombres ("nos") que implican la inclusión del autor del graffiti en el grupo de hablantes. La rima es una constante en el mensaje al estilo de los eslóganes comerciales o los cánticos que se corean en las manifestaciones, así como los enunciados con la fuerza ilocutiva de amenaza: "El miedo va a cambiar de bando".

Todos los graffitis pertenecientes a este subtipo están firmados o complementados con el símbolo feminista o transgénero (a veces combinados con el símbolo de anarquía).

El léxico se centra en metáforas sobre la guerra o en lexemas que se refieren a la violencia, siendo los más comunes en el corpus "muerte", "miedo" y "guerra”. Este tipo de graffiti describe la presencia de las mujeres en la sociedad como una batalla (Lakoff y Johnson, 1980: 81) y, de manera similar, la relación con el patriarcado como una guerra (figura 2). Las imágenes abajo ilustran estas ideas.

\section{FIGURA 1}

En caso de duda, tú la viuda

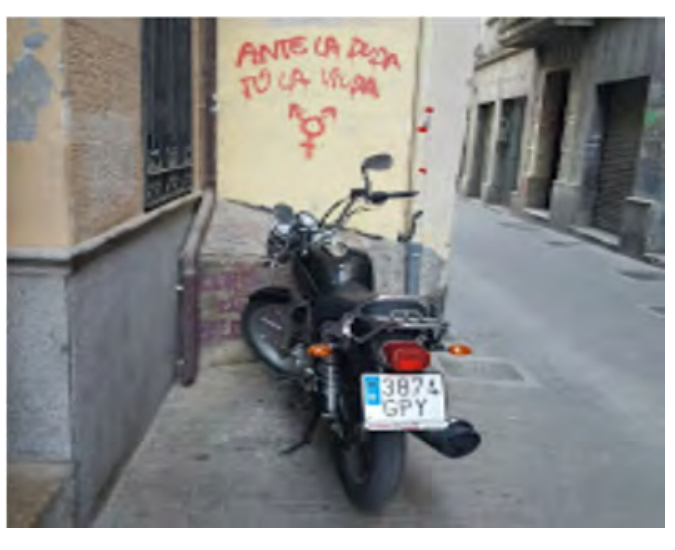

\section{FIGURA 2}

Estamos en guerra

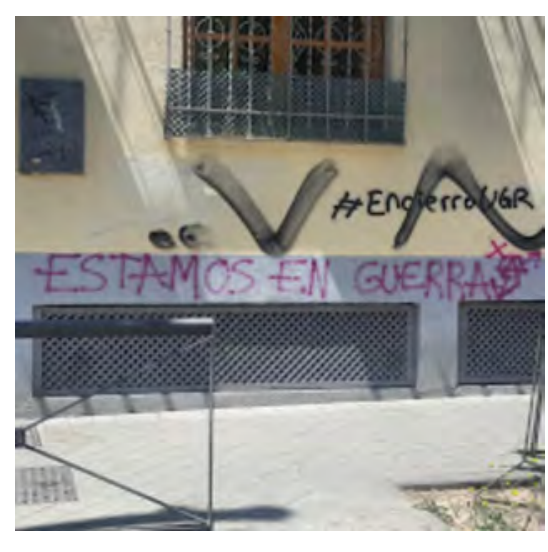




\section{b) Graffiti antisistema}

Waldner y Dobratz (2013) afirman que el graffiti es una táctica de resistencia que desafía las relaciones de poder, en particular el graffiti político, que, aunque puede ser considerado una forma ligera de protesta, tiene la capacidad de reflejar conflicto. Además está pensado y creado para su consumo público (Hanauer, 2011). En el corpus, estas tres funciones se expresan abiertamente, ya que todo graffiti político transmite discursos antihegemónicos en la sociedad española, es decir, aquellos que giran sobre la anarquía, los sentimientos republicanos o la oposición frontal a la monarquía, la privatización del Estado, la crítica a las fuerzas de seguridad y a los líderes políticos mundiales, o expresan un sentimiento de solidaridad en relación a los últimos acontecimientos más relevantes en la sociedad española (como el referéndum de Cataluña).

La exhortación a la clase trabajadora a movilizarse y a rebelarse contra las clases sociales altas junto con la llamada para instaurar el sistema anarquista constituyen el subgrupo más numeroso. Los lexemas más frecuentes proceden de la teoría marxista, como "proletario", "clase trabajadora" o "lucha de clases". Algunos mensajes están acompañados por imágenes que refuerzan el mensaje escrito de forma metafórica, como las cadenas rotas (figura 3) o las víboras (figura 4), que aluden al sistema político opresivo dominante junto con el símbolo de la anarquía.

\section{FIGURA 3}

Rompamos las cadenas. Destruyamos el Estado

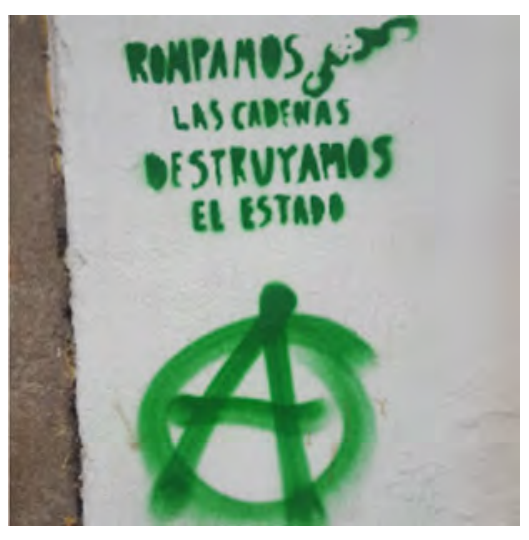

\section{FIGURA 4}

Son víboras. Con tu voto los alimentas

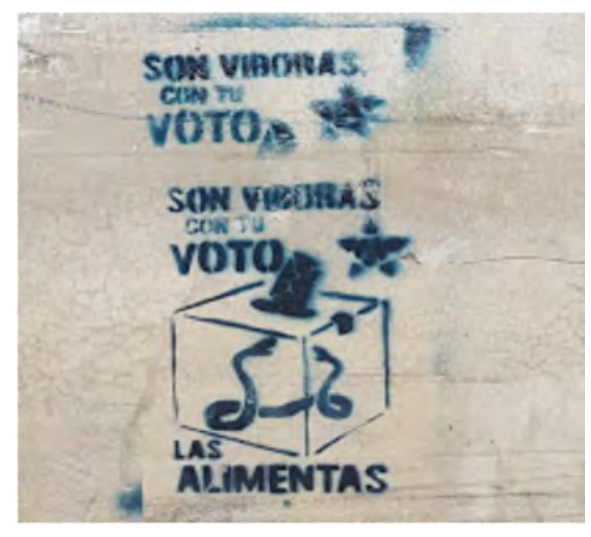

Las fuerzas de seguridad nacional, los dictadores históricos (figura 5) o los políticos en general son objeto de dura crítica en las paredes. La policía está siempre asociada con imágenes relacionadas con la violencia (figura 6) y es descrita a través del uso de modificadores como "mercenarios" o "terroristas".

\section{c) Graffiti anticapitalista}

Otro subtipo de graffiti es el que especificamente propaga un sentimiento antisistema fundamentalmente centrado en tres grandes áreas: la crítica al consumismo, al capitalismo y a la 


\section{FIGURA 5}

Pequeña sugerencia para hijos de puta. Sigan a su líder

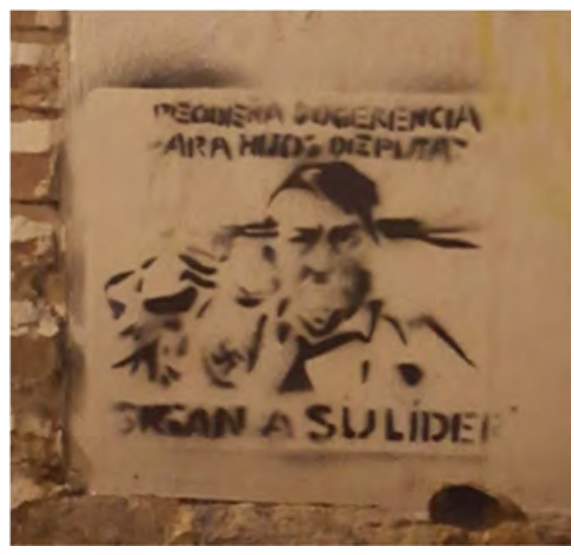

\section{FIGURA 6}

Así se construye España

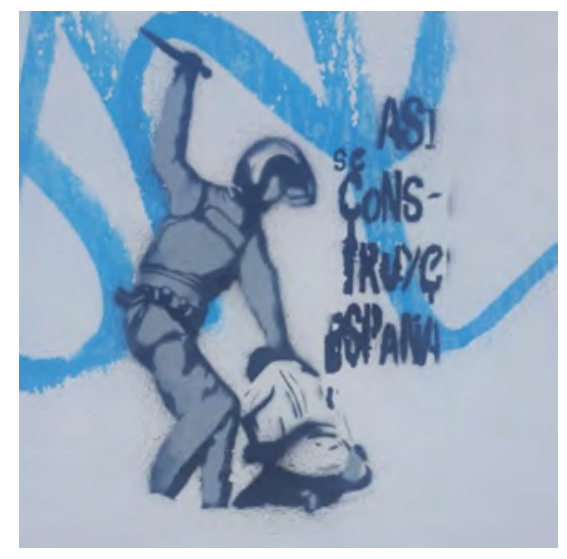

desinformación proporcionada por los medios de información. La mayoría de los mensajes están realizados sintácticamente por sintagmas y los términos léxicos más habituales pertenecen al campo léxico del intercambio comercial como "tiendas" (figura 7) o "consumo" (figura 8).

\section{FIGURA 7}

Tiendas Ilenas, vidas vacías

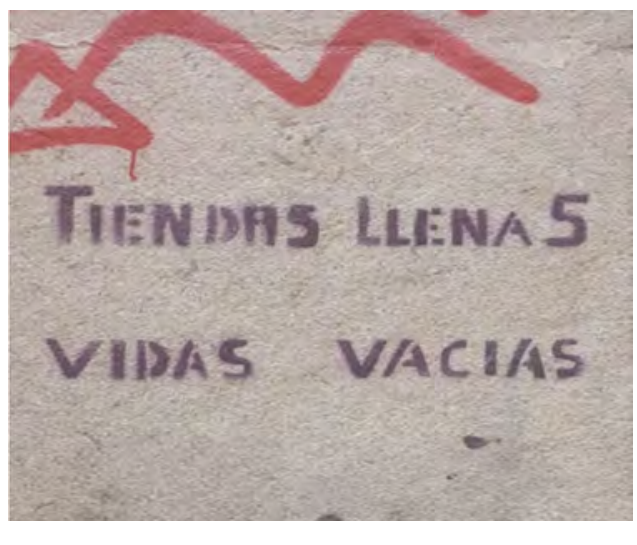

\section{FIGURA 8}

Zona de consumo zombi

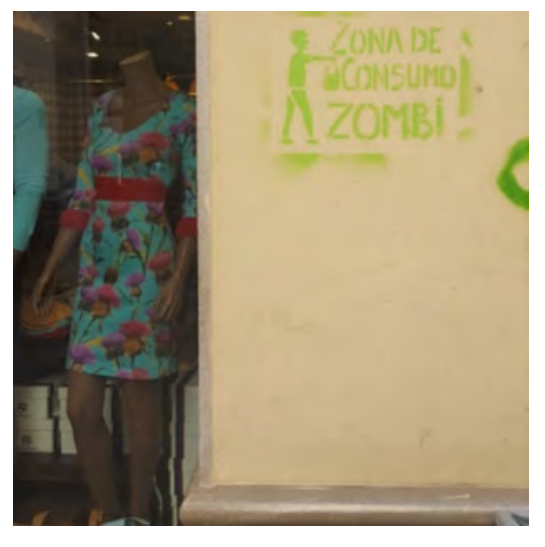

Los mensajes anticapitalistas se centran en el sistema bancario y su excesiva presencia en las vidas de los ciudadanos. Los términos más frecuentes de este tipo de graffitis son "banco"y “capital”.

La desinformación proporcionada por los medios de comunicación es el tema central de un pequeño grupo de graffitis que aluden a la televisión como fuente de información tóxica y sesgada. Las estructuras lingüísticas de presente en este subtipo son diversas y van desde las órdenes estrictas del imperativo en la figura 9 hasta la advertencia mucho más suave que se ve en la figura 10. 


\section{FIGURA 9}

Kill your television (mata a tu televisión)

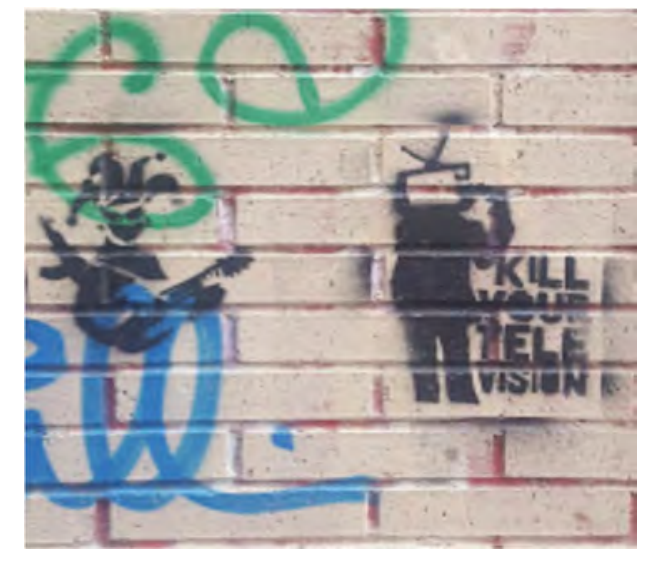

\section{FIGURA 10}

Si quieres vivir ciego, enciende las noticias

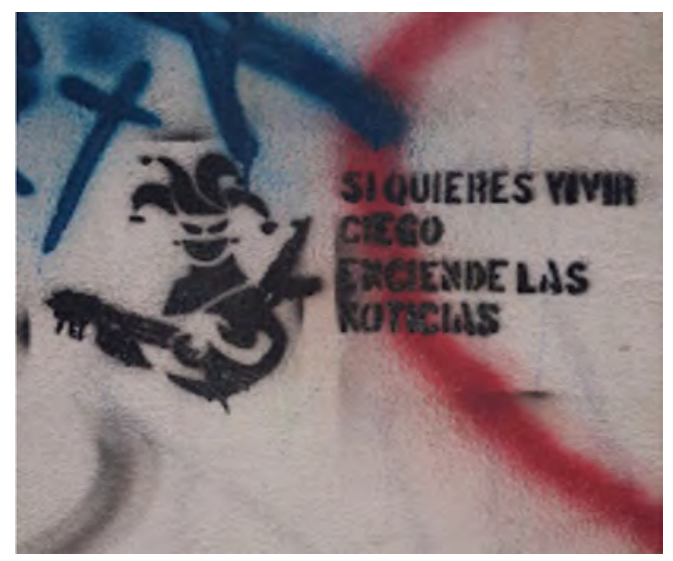

Muchos de los graffitis de este grupo, así como en el tipo antisistema, aparecen "firmados" por la figura de un arlequín (figuras 9 y 10). Además de los tres elementos centrales del acto comunicativo (emisor, receptor y mensaje), en su teoría de la enunciación, Ducrot (1984) introduce el "locutor" como el participante que parece ser responsable del enunciado o el sujeto discursivo presente en cada mensaje.

\section{d) Graffiti anticlerical}

El discurso del graffiti anticlerical se dirige directamente a la Iglesia católica. Los mensajes enfatizan la hipocresía inherente a las tradiciones o políticas adoptadas por ella. Todos los graffitis de este grupo son multimodales (incluyen una imagen) y los textos son sintagmas, no proposiciones, en los que uno de los constituyentes es un término asociado con el campo léxico de la religión (“Dei”, "Santa”) y el premodificador es el elemento que introduce la crítica ("estafa”, "gay" o "vagina”). Los sintagmas son descriptivos, inmediatos y más directos que las proposiciones especialmente cuando van acompañados de una imagen, como se puede ver en las figuras 11 y 12.

\section{e) Graffiti pro derechos de los animales}

Otro subtipo de graffiti es el que transmite un fuerte mensaje en favor de los derechos de los animales. El veganismo, a pesar de ser una tendencia emergente en el mundo ${ }^{8}$, es todavía un movimiento minoritario, si bien en auge, en España, de ahí que este tipo de graffiti esté

8 Para ver las tendencias de los últimos años sobre el veganismo, consúltense las estadísticas en el siguiente enlace: https://www.vegansociety.com/news/media/statistics. 


\section{FIGURA 11}

Opus Gay

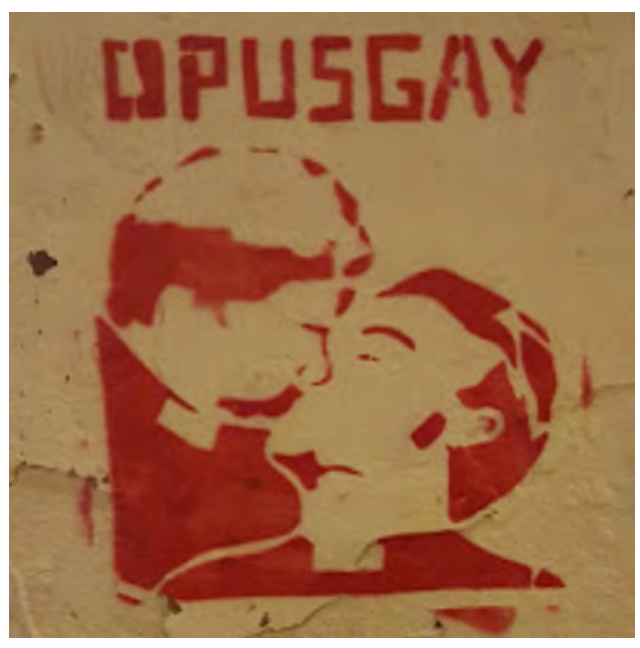

\section{FIGURA 12}

Del 16 al 23 de marzo: Estafa Santa

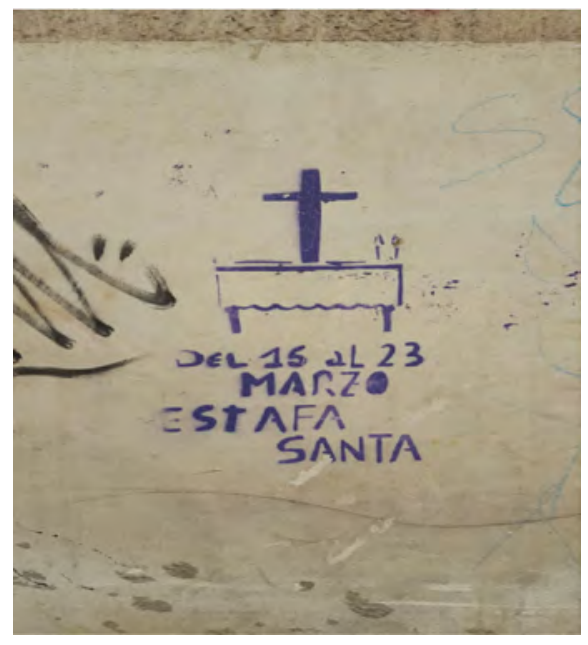

asociado con la marginalidad de una comunidad todavía no lo suficientemente visible. Las estructuras lingüísticas de este tipo de graffiti son más complejas que las encontradas en otros subtipos. El campo léxico alrededor del cual la mayoría de estos graffitis giran es el binomio vida vs. muerte, de ahí que los lexemas más frecuentes sean "vida", "vidas", "cadáver" o "asesino", en ejemplos tales como "El deseo de vivir no distingue entre especies" (figura 13) o "La vida no tiene precio. Los animales no somos objetos".

Mención especial merecen los graffitis que se refieren a la tauromaquia, como en la figura "Asesino a sueldo" (figura 14), ya que es un tema muy controvertido que ha dividido a la sociedad española entre defensores y detractores. El graffiti, de nuevo, saca a la luz pública el comentario social de uno de los temas más debatidos en el país.

\section{FIGURA 13}

El deseo de vivir no distingue entre especies

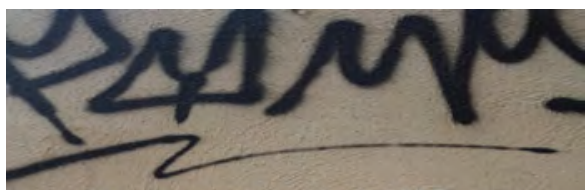

EL DESEO DE VIVIR ND DISTINGUE EATTRE ESTPECASS

\section{FIGURA 14}

Asesino a sueldo

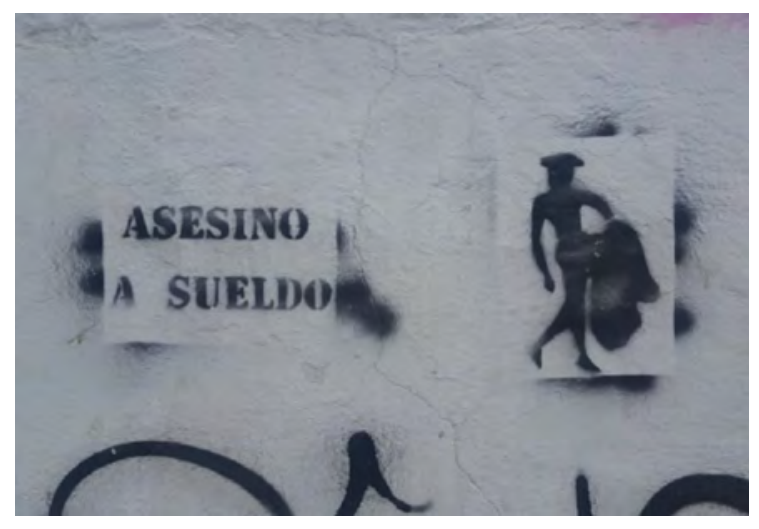




\section{f) Graffiti poético y filosófico}

Este es el subgrupo más numeroso (Gándara, 2002). La diversidad de estructuras y contenido es sobresaliente, desde preguntas retóricas (figura 15) hasta enunciados que promueven la reflexión pasando por ruegos realizados a través de imperativos. Los temas son variados y normalmente incluyen pensamientos sobre la humanidad (figura 16), la sociedad, el mundo y el/la autor/a.

Los graffitis de este tipo no contienen ningún tipo de crítica social (al menos no de manera explícita como el resto de subtipos que hemos visto anteriormente) contra ningún tipo de estructura de poder o mayoría social, sino que son más bien íntimos, personales e individuales. Algunos son ejemplos de hipocodificación (Eco, 1975), porque el código no es fácil de interpretar por el lector y el mensaje es hermético.

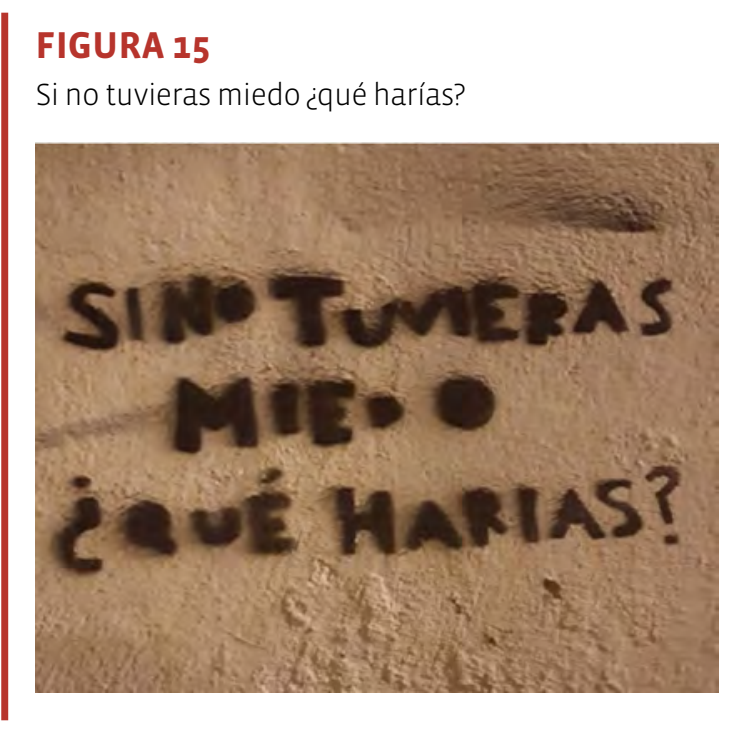

\section{FIGURA 16}

Fuck humans

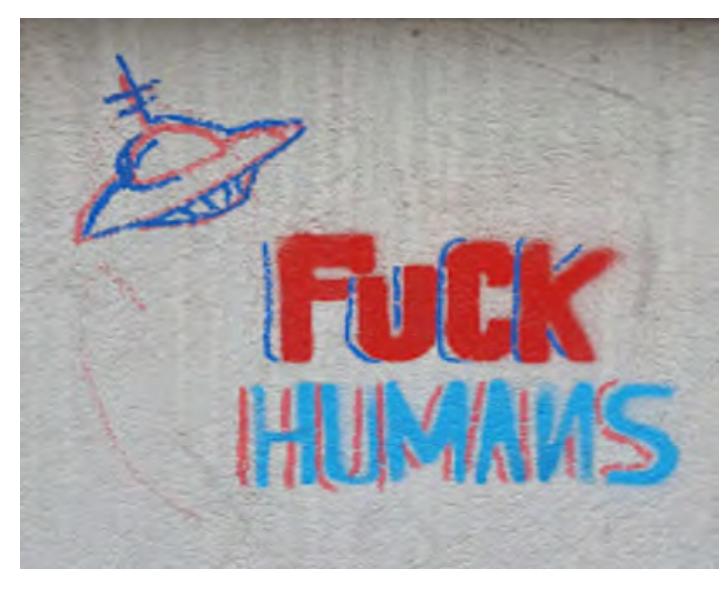

\section{Proyección didáctica del graffiti en la enseñanza de lenguas}

El análisis crítico del discurso de los graffitis compilados en Granada puso de relieve la proyección didáctica del graffiti como herramienta pedagógica para la clase de español como lengua extranjera. El graffiti, como género que nace motivado por la necesidad de visibilización de las minorías sociales, es idóneo para fomentar el pensamiento crítico y formar ciudadanos responsables y comprometidos.

El corpus de graffiti que proponemos como modelo para las clases de español para extranjeros además engloba muchos de los temas transversales que contempla la ley, como la crítica de la sociedad consumista, la (des)información proporcionada por los medios de comunicación, la violencia contra la mujer o los derechos de los animales. 
Las características del graffiti se adaptan perfectamente a la descripción de las competencias comunicativa, lingüística, sociolingüística y pragmática descritas por el MCER. El graffiti es además un tipo de texto que equilibra las competencias pluriculturales y plurilingües, es decir, el estudio de los aspectos más formales de la lengua, así como de los aspectos contextuales en los que se produce.

La competencia lingüística que el MCER define como "el conocimiento de los recursos formales y la capacidad para utilizarlos. A partir de estos componentes, se pueden articular y formular mensajes bien formados y significativos" (2002: 120) y las subcompetencias (léxica, gramatical, semántica, fonológica, ortográfica y ortoépica) albergan un gran número de posibilidades pedagógicas a través del graffiti, sobre todo aquellas no focalizadas en el modo de producción oral (fonológica y ortoépica). En relación a las subcompetencias léxica y semántica, el contenido de nuestro corpus puede resultar de interés para el desarrollo de las mismas, por ejemplo aprovechando la numerosa presencia de metáforas y léxico belicista que encontramos en el graffiti feminista ("guerra”, lucha”, "batalla” o "revolución”) y el de carácter más sociopolítico presente en el graffiti antisistema o anticapitalista (“clases", "proletariado", "obrero" o "capital”). En relación a la subcompetencia gramatical, el corpus contiene multitud de ejemplos en los que podemos analizar un gran abanico de patrones oracionales que van desde las estructuras más sencillas ("Sonríe") hasta construcciones más complejas como las frecuentes en el graffiti feminista ("Yo lo abortaría por si sale policía", "No somos víctimas, somos supervivientes"), sin olvidar la ironía o el doble sentido que impera en el graffiti anticlerical (“Estafa Santa”, “Opus Gay”). La subcompetencia ortográfica también puede ser estudiada a través del graffiti puesto que casi todos los textos del corpus contienen una correcta ortografía (incluido el uso de los signos de puntuación), con la excepción de un par de casos en los que se sustituyó la grafía "qu” por "k”, un aspecto que el docente podría incluso considerar de interés para discutir en el aula.

La dimensión del uso social de la lengua queda definida dentro de las competencias sociolingüística y pragmática dado que la lengua es eminentemente un fenómeno sociocultural y funcional. Aspectos mencionados específicamente por el MCER dentro de la competencia sociolingüística (2002: 13) como los marcadores lingüísticos de relaciones sociales, las expresiones de sabiduría popular o las diferencias de registro pueden enseñarse a través del graffiti. Algunas características no podrán explicarse por su presencia explícita, sino por su ausencia en el texto (la audiencia del graffiti no se selecciona por criterios de registro, por ejemplo), pero sí que existen marcadores que ordenan las relaciones entre generaciones, sexos, clases y grupos sociales, como vimos de manera muy clara en los graffitis feministas, antisistema, anticapitalista y pro derechos de los animales.

La competencia pragmática, muy relacionada con la sociolingüística, que se centra en la destreza para saber utilizar los recursos lingüísticos de manera efectiva dependiendo de la función comunicativa (2002: 13), es principal en todas las subcategorías de graffiti que hemos 
visto. Así, hemos estudiado la función de exhortación propia del graffiti antisistema y anticapitalista que pretende movilizar a un sector de la población para que tomen conciencia o acción, la denuncia de los abusos del sistema patriarcal frecuente en el graffiti feminista, la visibilización de la opresión que sufren los animales por parte de ciertos humanos del graffiti pro derechos de los animales y la función de reflexión que provoca el graffiti filosófico.

\section{Conclusiones}

Tal y como se expuso en la introducción, el objetivo fundamental de este trabajo es poner de relieve las ventajas didácticas del estudio del graffiti en una asignatura de enseñanza de español como lengua extranjera y abogar por su inclusión en el currículo académico. El potencial didáctico de este género popular de la subcultura urbana se basó en nuestro análisis previo sobre discurso contenido en un corpus compilado en la ciudad de Granada que desveló la profunda crítica social frente a los poderes hegemónicos llevada a cabo por diferentes grupos minoritarios. El graffiti emerge como un acto comunicativo canalizador de la voz de minorías socialmente invisibles a través de la apropiación ilícita del espacio urbano. El concepto de transversalidad y la enseñanza de valores a través de los contenidos académicos refuerza además la incorporación del graffiti al currículo.

Es justo este aspecto social del graffiti el que lo convierte en una herramienta idónea para fomentar el pensamiento crítico en el alumnado, así como lo conecta con la noción de educación social promulgada por Freire (1971). El inventario de competencias comunicativas y sus subcompetencias lingüística, sociolingüística y pragmática descrito por el MCER apoya el uso del graffiti como recurso didáctico.

\section{Bibliografía citada}

Baudrillard, Jean, 1974: Kool Killer ou l'insurrection par les signes, Papers 3, Barcelona: Barral Editors.

BLACK, Susan, 2005: "Teaching students to think critically”, The Education Digest 70 (6), 42-47.

Bloom, Benjamin S., Max D. Engelhart, Edward J. Furst, Walker H. Hill y David R. Krathwohl, 1956: Taxonomy of educational objectives: The classification of educational goals. Handbook I: Cognitive domain, New York: David McKay Company.

Blume, Regina, 1985: “Graffiti” en Teun van DıJk (ed.): Discourse and Literature. New Approaches to the analysis of literary genres, Amsterdam: John Benjamins Company, 137-148.

Breva Claramonte, Manuel, y José Ignacio García Alonso, 1993: "Categories, Morphological Features, and Slang in the graffiti of a United States Western University", Revista Alicantina de Estudios Ingleses 6, 19-31. 
CHor, S. Chee, 2003: An investigation into the changes in perceptions of and attitudes towards learning English in a Malaysian college. Tesis doctoral no publicada, Exeter: University of Exeter.

Colı, César, 1991: Psicología y currículum, Barcelona: Paidós.

Diaz Barriga, Ángel, 2006: "La educación en valores: Avatares del currículum formal, oculto y los temas transversales", Revista Electrónica de Investigación Educativa 7 (2), 1-15.

DUCROT, Oswald, 1984: Le dire et le dit, Paris: Minuit.

DURon, Robert, Barbara LIMBACH y Wendy WaUGH, 2006: "Critical thinking framework for any discipline", International Journal of Teaching and Learning in Higher Education 17 (2), 160-166.

Eco, Umberto, 1975: A Theory of Semiotics, Indiana: Indiana University Press.

FalRclough, Norman, 1995: Critical Discourse Analysis: The Critical Study of Language, London: Longman.

Freire, Paulo, 1971: Pedagogy of the Oppressed, New York: Herder \& Herder.

Freire, Paulo, 1994: Pedagogy of Hope, New York: Continuum.

GadsBy Jane M. 1995: "Looking at the Writing on the Wall. A Critical Review and Taxonomy of Graffiti Texts" [http://www.graffiti.org/faq/critical.review.html, fecha de consulta: 24 de marzo de 2018].

Gandara, Lelia, 2002: Graffiti, Buenos Aires: Universidad de Buenos Aires.

Gari, Joan, 1995: La conversación mural. Ensayo para una lectura del graffiti, Madrid: FUNDESCO.

GIRoux, Henry A., 2010, "Rethinking education as the practice of freedom: Paulo Freire and the promise of critical pedagogy", Policy Futures in education 8 (6), 715-721.

Halpern, Diane F., 2003: Thought and knowledge: An introduction to critical thinking, Mahwah, NJ: Erlbaum.

Hanauer, David I, 2011: "The discursive construction of the separation wall at Abu Dis", Journal of Language and Politics 10, 301-21.

Hidalgo Tenorio, Encarnación, 2011: "Critical Discourse Analysis, An overview”, Nordic Journal of English Studies 10, 183-210. 
Instituto Cervantes, 2002: Marco común europeo de referencia para las lenguas [https://cutt.ly/ oriTugt, fecha de consulta: 3 de marzo de 2019].

KelLING, George, y James WILSON, 1982: "Broken Windows", The Atlantic [https://cutt.ly/VriTybL, fecha de consulta: 4 de marzo de 2018].

Lakoff, George, y Mark Johnson, 1980: Metaphors we live by, Chicago: University of Chicago Press.

LAUER, Thomas, 2005: "Teaching critical-thinking skills using course content material”, Journal of College Science Teaching 34 (6), 34-44.

Martinez, María José, 1995: Los temas transversales, Buenos Aires: Magisterio del Río de la Plata.

Ministerio de Educación, Cultura y Deporte, 2002: Plan curricular del Instituto Cervantes [https:// cutt.ly/ZriTah4, fecha de consulta: 28 de marzo de 2019].

Munévar, Dora I., y Marta L. VILlaseñor, 2005: “Transversalidad de género. Una estrategia para el uso político-educativo de sus saberes”, La Ventana 21, 44-68.

Pérez SendRa, Ramón (ed.), 2014: Escenas del graffiti en Granada, Granada: Ciengramos.

Pérez Sendra, Ramón, 2017: "El graffiti como recurso didáctico en el ámbito educativo. El caso de Granada”, Universidad, Escuela y Sociedad [https://cutt.ly/griTtlg, fecha de consulta: 20 de junio de 2019].

Real Academia Española [https://dle.rae.es/graffiti, fecha de consulta: 24 de abril de 2018].

Sılva, Armando, 1988: Una ciudad imaginada. Graffiti, expresión urbana, Bogotá: Universidad Nacional de Colombia.

Tовón Sergio, 2013: Los proyectos formativos: Transversalidad y desarrollo de competencias para la sociedad del conocimiento, Instituto CIFE: México D. F. [https://bit.ly/37iPoVr, fecha de consulta: 21 de agosto de 2019].

Trave Gonzalez, Gabriel, y Francisco J. Pozuelos EstradA, 1999: "Superar la disciplinariedad y la transversalidad simple: hacia un enfoque basado en la educación global", Investigación en la Escuela 37, 5-13.

Ugarte Garcia, Maria del Carmen, 2012: "Pintadas y Fraseología" en Antonio Pamies Bertran, Lucía Luque Nadal y José Manuel Pazos Bretaña (eds.): Phraseology and Discourse: Cross-Linguistic and Corpus-Based Approaches, Baltmannsweiler: Schneider Verlag, 431-441. 
Van Leeumen, Theodore, 2009: "Critical Discourse Analysis" en Jan Renkema (ed.): Discourse, of Course: An Overview of Research in Discourse Studies, Amsterdam: John Benjamins, 277-291.

Waldner, Lisa K., y Betty A. Dobratz, 2013: "Graffiti as a form of contentious political participation”, Sociology Compass 7 (5), 377-389.

Zabala, Antoni, 1995: La práctica educativa. Cómo enseñar, Barcelona: Grao. 